Revista Eletrônica em Gestão, Educação e Tecnologia Ambiental Santa Maria, v. 19, n. 1, jan.-abr. 2015, p. 248-253

Revista do Centro de Ciências Naturais e Exatas - UFSM

\title{
Horta na escola: incentivo ao cultivo e a interação com o meio ambiente
}

\author{
Garden at school: encouraging the culture and interaction with the environment
}

\author{
Élen Gomes de Jesus Eno ${ }^{1}$, Renata Raimundo de Luna ${ }^{1}$, Renato Abreu Lima ${ }^{2,3}$
}

\begin{abstract}
${ }^{1}$ Graduação em Ciências Biológicas, Faculdade São Lucas, Porto Velho, RO, Brasil.
${ }^{2}$ Doutorando em Biodiversidade e Biotecnologia - BIONORTE, Universidade Federal de Rondônia, Porto Velho, RO, Brasil; 32Docente da Universidade Federal do Amazonas, UFAM, Instituto de Natureza e Cultura, Campus Benjamin Constant, AM, Brasil; E-mail: renatoabreu07@hotmail.com
\end{abstract}

\begin{abstract}
Resumo
A horta de plantas medicinais e de hortaliças é um meio de incentivar a comunidade em conhecer melhor os fitoterápicos e de ter uma alimentação saudável, além de estabelecer uma educação ambiental para conseguir a sensibilização coletiva. O presente trabalho teve como objetivo desenvolver práticas pedagógicas na Escola Estadual de Ensino Fundamental Padre Mário Castagna, em Porto Velho, Rondônia, proporcionando o aprendizado sobre a importância de uma boa alimentação com hortaliças sem qualquer tipo de agrotóxicos e da preservação do meio ambiente. As hortaliças de pequeno porte foram cultivadas em pneus, tendo em vista que sua matéria prima tem longa durabilidade e com intuito de retirá-los do meio ambiente, enquanto que as ramificadas foram plantadas no solo preparado com adubo e terra preta, assim como nos pneus. Como resultado, obteve-se hortaliças muito saudáveis e bonitas, e as mudas de plantas medicinais sobreviveram e estão crescendo com rapidez, assim preservando o meio ambiente. Conclui-se que relacionando os fitoterápicos ao cotidiano e uma merenda escolar mais rica em nutrientes e vitaminas, temos então acrescentado benefícios para essa comunidade, e ainda a participação e interação de todos em manter o projeto vivo da horta na escola.
\end{abstract}

Palavras-chave: Horta escolar. Educação. Sensibilização. Motivação.

\begin{abstract}
The garden of medicinal plants and vegetables is a means of encouraging the community to better understand herbal and have a healthy diet, and to establish an environmental education to achieve the collective awareness. The present work aimed to develop pedagogical practices at the State Primary School Father Mario Castagna, in Porto Velho, Rondônia, providing learning about the importance of good nutrition with vegetables without any pesticide and environment preservation. Small vegetables were grown in tires, considering that its raw material is long lasting and with the intention of removing them from the environment, while branched plants planted in prepared soil with compost and black soil, as well as the tires. As a result, we obtained very healthy and beautiful vegetables, and seedlings of medicinal plants survived and are growing rapidly, thus preserving the environment. It is concluded that herbal relating to everyday life and a richer school meals in nutrients and vitamins, so we added benefits to this community, and also the participation and interaction of all keep the project alive in the garden at school.
\end{abstract}

Keywords: school Horta. Education. Awareness. Motivation. 


\section{Introdução}

Com a modernidade, facilidade de compra e aumento do poder aquisitivo das famílias, modifica os costumes das populações interferindo diretamente na cultura e nos hábitos. Assim a população troca os hábitos tradicionais pelos modernos, exemplo disso é a substituição dos remédios caseiros, preparados a partir de plantas medicinais, por remédios químicos, encontrados em farmácias e drogarias e ainda na compra de hortaliças com agrotóxicos em supermercados. Isso resulta na diminuição gradativa do uso de fitoterápicos, que pode ocasionar a perda dos conhecimentos tradicionais sobre a utilização de plantas medicinais na prevenção e tratamento de enfermidades e ainda uma alimentação mais saudável com o cultivo de hortaliças. Temos então, a educação como ponto chave para conseguir a sensibilização coletiva, uma vez, que a educação ambiental é descrita como obrigatoriedade na Constituição Brasileira. Todavia, a criação de hortas nas escolas de ensino público é um meio de se efetivar o que já está instituído na lei.

A prática da implantação de uma horta escolar pode proporcionar várias atividades didáticas, oferecendo diversas vantagens para a comunidade escolar. Dentre elas, proporciona uma grande variedade de plantas medicinais e hortaliças incrementando na relação teórico-prática, permitindo ampliar o conhecimento sobre o cultivo e manejo das hortas para a comunidade, assim como o acesso as informações da importância do uso correto das ervas proporcionando melhores resultados na prevenção e cura de determinadas enfermidades. Portanto, o envolvimento da escola nesse projeto auxilia na promoção da saúde e efetiva a sensibilização ambiental.

As hortas inseridas no ambiente escolar podem ser um laboratório vivo que possibilita o desenvolvimento de diversas atividades pedagógicas em educação ambiental e alimentar, unindo teoria e prática de forma contextualizada, auxiliando no processo ensino-aprendizagem, estreitando relações através da promoção do trabalho coletivo e cooperação solidária entre os agentes sociais envolvidos (MORGADO, 2006).

A horta na escola pode servir como fonte de alimentação e atividades didáticas, oferecendo grandes vantagens às comunidades envolvidas, como a obtenção de alimentos de qualidade a baixo custo e também o envolvimento em programas de alimentação e saúde desenvolvidos pelas escolas (NOGUEIRA, 2005).

O objetivo deste trabalho é desenvolver práticas pedagógicas na Escola Estadual de Ensino Fundamental Padre Mário Castagna, utilizando como estratégia a criação, desenvolvimento e cultivo da horta que proporcionará o aprendizado sobre a importância de uma alimentação saudável e preservação do meio ambiente.

\section{Metodologia}

A presente pesquisa teve como base a metodologia de pesquisa-ação com uma abordagem qualitativa. Segundo Tripp (2005), a pesquisa-ação requer ação tanto nas áreas da prática quanto da pesquisa de modo que, em maior ou menor medida, terá características tanto da prática rotineira quanto da pesquisa científica.

Pedrini et al. (2002) ressalta que a pesquisa-ação usada na Educação Ambiental parte do diálogo entre a ciência e o senso comum. A maior dificuldade da pesquisa-ação, no nosso ponto de vista, está situada na relação entre o saber popular, ou conhecimento comum, ou o conhecimento dado pela vida, e o conhecimento científico, ou discurso racional. 
O presente projeto foi realizado no período de setembro a novembro de 2014 seguindo as etapas abaixo elencadas:

1. Apresentação do Projeto para a Direção da Escola;

2. Aprovação do Projeto;

3. Coleta de Material Proveniente de Reutilização (pneus inutilizados doados por borracharias do entorno).

4. Implantação da Horta (Preparo da terra, solo e plantio de sementes);

5. Monitoramento de Crescimento e Regagem;

6. Elaboração dos Resultados.

Após aprovação da diretoria este projeto passou a integrar o quadro fixo de atividades do Programa Mais Educação do Governo Federal e teve como público-alvo a comunidade escolar sendo desenvolvido na Escola Estadual de Ensino Fundamental Padre Mário Castagna pertencente à rede pública de Porto Velho - Rondônia.

Os materiais utilizados na horta foram: mudas de plantas medicinais; sementes de hortaliças; regador; terra preta; adubo; pneus e ferramentas (pá, boca de lobo, enxada e etc.).

Todo material utilizado na realização deste projeto é proveniente de doações de amigos e colaboradores, bem como investimento próprio. Os pneus foram utilizados como recipientes para plantio das sementes, pois sua matéria prima é de alta durabilidade sendo considerada esta, uma prática de reutilização ecologicamente correta. As plantas medicinais foram plantadas entre as hortaliças, tendo em vista, que algumas servem como repelente para afastar pragas e insetos.

No decorrer desse período a horta teve os dias de manutenção, que foi de duas a três vezes por semana, em caso de falta de nutrientes eram feitas reposição de adubo.

Para a implantação da horta, primeiramente foram cavados dezesseis buracos com aproximadamente $20 \mathrm{~cm}$ para enterrar os pneus (Figura 1), um após o outro para hortaliças de pequeno porte (sem ramos). Para as rasteiras (com ramos) foi preparado o solo com terra preta e adubo, em seguida semeado as sementes (Figura 2).

As identificações das espécies foram baseadas em (LORENZI; MATOS, 2008) e (LORENZI; SOUZA, 2008).
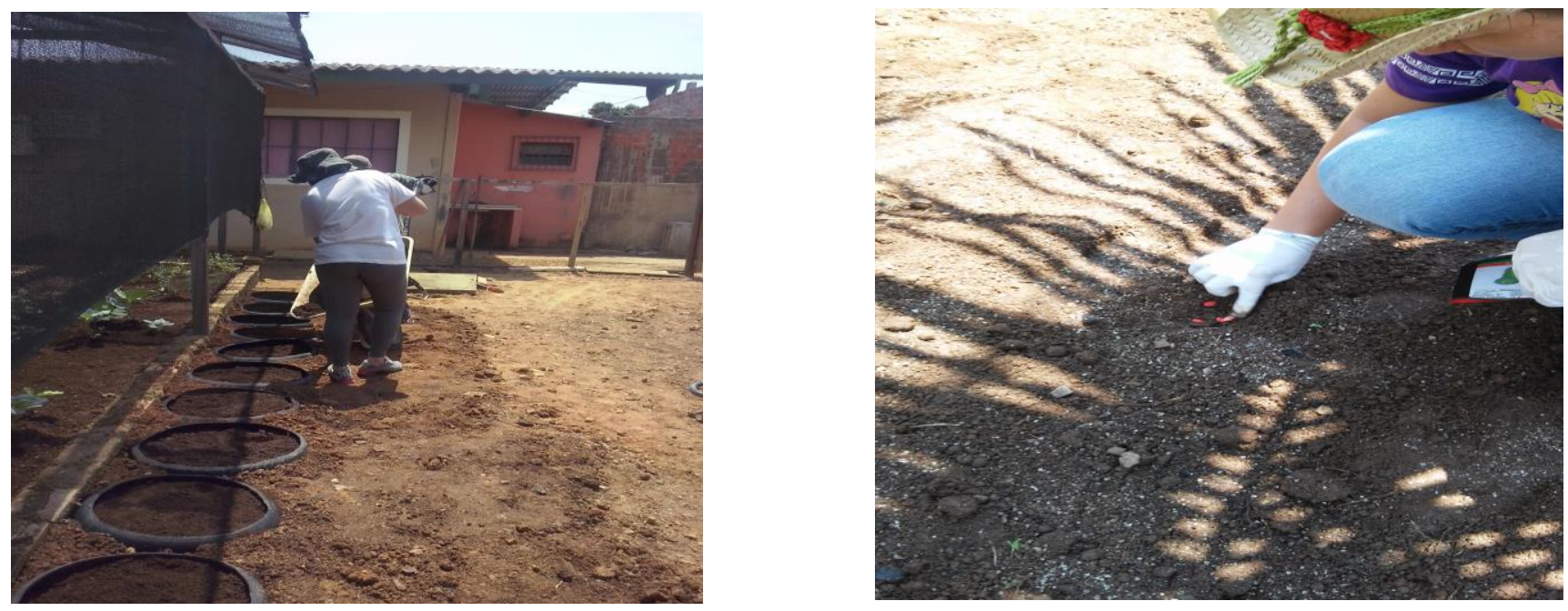

Figura 2 - Plantio das hortaliças com ramos.

Fonte: LUNA, 2014.

Para embasamento e maior facilidade na elaboração dos resultados utilizou-se o método por pesquisa documental e bibliográfica. 


\section{Resultados e Discussões}

Com a implantação da horta, profissionais da educação, alunos e pais de alunos, entusiasmados, começaram a trazer mudas e sementes para cultivar no local. Contribuindo, assim com a diversidade das espécies cultivadas.

Segundo Silva (2012), o Brasil tem a maior biodiversidade do planeta com cerca de $55 \mathrm{mil}$ espécies de plantas superiores conhecidas. A maioria é usada pelo ser humano como fonte de alimento, como matéria-prima para construção, como medicamentos para cura de enfermidades ou no uso de aromatizantes. Reconhece que o conhecimento tradicional de grupos sociais que fazem uso das plantas é a fonte essencial para a descoberta dos princípios ativos - substâncias capazes de exercer uma ação de cura - responsáveis no combate de doenças.

Havendo cada vez mais a busca das plantas medicinais e/ou seus derivados como agentes terapêuticos naturais. O estímulo ao uso destes fitoterápicos tem como objetivo: prevenir, curar ou minimizar os sintomas das doenças, com um custo mais acessível à população e aos serviços públicos de saúde, comparativamente aqueles obtidos por síntese química, que são, em geral, mais caros, devido às patentes tecnológicas envolvidas (MIGUEL \& MIGUEL, 1999).

Contudo, estes produtos naturais podem ser tão eficientes quanto os produzidos pela síntese química, logo a transformação de uma planta em um medicamento deve visar à preservação da integridade química e farmacológica do vegetal, garantindo a constância de sua ação biológica e a sua segurança de utilização, além de valorizar seu potencial terapêutico (MIGUEL \& MIGUEL, 1999).

O desenvolvimento de fitoterápicos inclui várias etapas e envolve um processo interdisciplinar, multidisciplinar e interinstitucional. As áreas de conhecimento envolvidas vão desde a antropologia botânica, botânica, agronomia, ecologia, química, fitoquímica, farmacologia, toxicologia, biotecnologia, química orgânica até a tecnologia farmacêutica (TOLEDO et al., 2003).

Hoje em dia, com a colaboração de toda a comunidade escolar, a horta tem muito mais alimentos do que no início projeto, desse modo continuará a produzir o ano letivo inteiro.

Para Cribb (2010), a horta escolar é o espaço propício para que as crianças aprendam os benefícios de formas de cultivo mais saudáveis. Além disso, aprendem a se alimentar melhor, pois como se sabe, as crianças geralmente não gostam de comer verduras e legumes e o fato de cultivar o alimento que levarão para casa os estimula a comê-los, especialmente quando conhecem a origem dos vegetais e sabem que são cultivados sem a adição de insumos químicos.

As atividades realizadas na horta escolar contribuem para os alunos uma compreensão da necessidade da preservação do meio ambiente escolar; desenvolve a capacidade do trabalho em equipe e da cooperação; proporciona um maior contato com a natureza, já que crianças dos centros urbanos estão cada vez mais afastadas do contato com a natureza. Tais atividades auxiliam no desenvolvimento da consciência de que é necessário adotarmos um estilo de vida menos impactante sobre meio ambiente bem como a integração dos alunos com a problemática ambiental vivenciada a partir do universo da horta escolar (CRIBB, 2010).

Ruscheinsky (2002) aponta para a necessidade de conferir a agricultura um caráter mais autossustentável e menos agressivo à natureza como atualmente é a agricultura convencional. Nesse sentido a chamada agricultura ecológica surge como uma alternativa que confere inúmeros benefícios aos produtores, aos consumidores e para o meio ambiente como um todo. Este tipo de agricultura exclui do seu sistema de produção o uso de fertilizantes sintéticos de alta solubilidade e agrotóxicos, além de reguladores de crescimento e aditivos sintéticos para a alimentação animal. A recomendação é que sejam utilizados os estercos animais, rotação de culturas, adubação verde, compostagem e controle biológico de pragas e doenças. Este sistema procura manter a estrutura e produtividade do solo, trabalhando em harmonia com a natureza. 
Como resultado obteve-se vários pontos positivos, além da escola receber o projeto, foi inserida nessa comunidade escolar, o incentivo de cultivar plantas e hortaliças para o próprio consumo.

As espécies de hortaliças cultivadas foram: alface (Lactuca sativa L.); rúcula (Eruca vesicaria (L) Cav.); almeirão (Cichorium intybus L.); couve-manteiga (Brassica oleracea Var. acephala); cebolinha-decheiro (Allium fistulosum L.); coentro (Coriandrum sativum L.); maxixe (Cucumis anguria L.); abóbora (Cucurbita pepo L.) e feijão (Phaseolus vulgaris L.).

As espécies de plantas medicinais cultivadas foram: arruda (Ruta graveolens L.); hortelã (Mentha spp.); babosa (Aloe vera (L.) Burm. f.); pata de vaca (Bauhinia cheilantha (Bong.) Steud.); terramicina (Alternanthera brasiliana (L.) Kuntze) e manjericão (Ocimum basilicum L.), sendo duas de cada espécie com exceção do manjericão e da terramicina que foi apenas uma.

Segundo Pinto (2008) e Di Stasi; Hiruma-Lima (2002), as plantas medicinais abaixo citadas têm as respectivas indicações terapêuticas. Ressaltando que o uso dessas ervas medicinais é para enfermidades de baixa gravidade.

Tabela 1 - Indicação terapêutica das plantas medicinais.

\begin{tabular}{|c|c|c|}
\hline Nome Popular & Nome Científico & Indicação Terapêutica \\
\hline Arruda & Ruta graveolens $\mathrm{L}$. & $\begin{array}{l}\text { Convulsão; dor de cabeça; } \\
\text { febre; cólica; hemorragia; } \\
\text { verme; infecção; reumatismo. }\end{array}$ \\
\hline Hortelã & Mentha spp & $\begin{array}{l}\text { Diarreia; verminose; vômito; } \\
\text { tosse; abrir apetite; tétano; } \\
\text { digestivo. }\end{array}$ \\
\hline Babosa & Aloe vera (L.) Burm. f. & $\begin{array}{l}\text { Cicatrizante; queimaduras; } \\
\text { queda de cabelo; infecções na } \\
\text { pele. }\end{array}$ \\
\hline Pata de vaca & $\begin{array}{l}\text { Bauhinia cheilantha (Bong.) } \\
\text { Steud. }\end{array}$ & $\begin{array}{l}\text { Diabetes; colesterol; pedra nos } \\
\text { rins; rins. }\end{array}$ \\
\hline Terramicina & $\begin{array}{l}\text { Alternanthera brasiliana (L.) } \\
\text { Kuntze }\end{array}$ & $\begin{array}{l}\text { Diarreia; infecções; tosse; dor de } \\
\text { garganta; } \quad \text { conjuntivite; } \\
\text { estômago. }\end{array}$ \\
\hline Manjericão & Ocimum basilicum $\mathrm{L}$. & $\begin{array}{l}\text { Tosse; dor de cabeça; gripe; } \\
\text { pneumonia; asma; cólica; } \\
\text { hemorragia; inflamação; } \\
\text { diurética; febre; fígado. }\end{array}$ \\
\hline
\end{tabular}

Quanto aos benefícios das hortaliças cultivadas estão sendo usadas na merenda escolar, com o intuito de uma alimentação mais saudável para os funcionários e alunos.

A execução decorreu com êxito em relação ao plantio e a interação dos colaboradores da escola em conhecer os fitoterápicos e cultivar hortaliças como meio de vida mais saudável.

\section{Conclusão}

Esse projeto proporcionou maior qualidade no conhecimento de botânica, relacionando as ervas medicinais ao cotidiano a partir do conhecimento popular e uso de alimentos mais saudáveis para a merenda escolar.

A interação de toda comunidade escolar foi de suma importância, onde houve responsabilidade por parte de todos em manter e preservar essa ação pedagógica, bem como o cultivo 
da horta. Além disso, que os hábitos e conhecimento sobre os fitoterápicos, e principalmente o hábito alimentar saudável com as hortaliças cultivadas na própria escola sejam posto em prática no cotidiano dos funcionários e alunos. Por fim, a sensibilização sobre a importância de preservar o meio ambiente, e de conhecer os fitoterápicos.

Contudo, em futuros projetos, abranger o cultivo de plantas frutíferas, para incrementar na merenda com sucos naturais e também comer frutos colhidos na própria escola.

\section{Agradecimentos}

À Escola Estadual de Ensino Fundamental Padre Mário Castagna, por nos receber e aceitar a implantação do nosso projeto e dar continuidade a horta.

\section{Referências Bibliográficas}

Cribb, S.L.S.P. (2010). Contribuições da educação ambiental e horta escolar na promoção de melhorias ao ensino, à saúde e ao ambiente. REMPEC - Ensino, Saúde e Ambiente.

DI Stasi, L.C.; Hiruma-Lima, C.A. (2002). Plantas Medicinais na Amazônia e na Mata Atlântica. São Paulo: Unesp.

Lorenzi, H.; Matos, F.J.A. (2008). Plantas Medicinais no Brasil: nativas e exóticas. São Paulo: Nova Odessa.

Lorenzi, H.; Souza, V.C. (2008). Botânica Sistemática: guia ilustrado para identificação das famílias de fanerógamas nativas e exóticas no Brasil, baseado em APG III. São Paulo: Nova Odessa.

Miguel, M.D.; Miguel, G.O. (1999). Desenvolvimento de fitoterápicos. São Paulo: Robe.

Morgado, F.S. (2006). A horta escolar na educação ambiental e alimentar: experiência do Projeto Horta Viva nas escolas municipais de Florianópolis. 2006. 45p. Centro de Ciências Agrárias. Universidade Federal de Santa Catarina, Florianópolis.

Nogueira, W.C.L. Horta na escola: uma alternativa de melhoria na alimentação e qualidade de vida. In: ENCONTRO DE EXTENSÃO DA UFMG, 8, 2005, Belo Horizonte. Anais... Belo Horizonte: UFMG, 2005, 48p.

Ruscheinsky, A. (2002). Educação ambiental: abordagens múltiplas. Porto Alegre: Artmed, 2002.

Pedrini, A.G. et al. (2002). Educação Ambiental: reflexões e práticas contemporâneas. Petrópolis: Vozes.

Pinto, L.N. (2008). Plantas medicinais utilizadas em comunidades do município de igarapé-miri, Pará: Etnofarmácia do município de igarapé-miri - Pará. 2008. 73-89p. Instituto de Ciências da Saúde. Programa de pós-graduação em Ciências Farmacêuticas. Universidade Federal do Pará, Belém.

Silva, F.R. Plantas Medicinais e Valorização dos Saberes Populares. Disponível em: <http://praticaescolarciencias.blogspot.com/2012/05/v-behaviorurldefaultvmlo_31.html>. Acesso em: 18 de mar. 2014.

Toledo, A.C.O. et al. (2003). Fitoterápicos: uma abordagem farmacotécnica. Bragança Paulista: Lecta, 2003.

Tripp, D. (2005). Pesquisa-ação: uma introdução metodológica. 2005. 447p. Educação e Pesquisa. Universidade de Murdoch, São Paulo, 2005. 